\title{
Prevalence of endodontic diseases: an epidemiological evaluation in a Brazilian subpopulation
}

\author{
Bruna Paloma de Oliveira', Andréa Cruz Câmara', Carlos Menezes Aguiar ${ }^{1}$
}

${ }^{1}$ Universidade Federal de Pernambuco - UFPE, Dental School, Department of Prosthodontics and Oral and Maxillofacial Surgery, Recife, PE, Brazil

Received for publication: June 27, 2016 Accepted: September 08, 2016

Correspondence to: Bruna Paloma de Oliveira Universidade Federal de Pernambuco, Centro de Ciências da Saúde, Departamento de Prótese e Cirurgia Bucofacial Av. Prof. Moraes Rego s/n, Cidade Universitária, 50670-901 Recife, PE - Brazil

Phone: $+55812126-8817$ E-mail: bruna_paloma@msn.com

\begin{abstract}
Aim: To determine the prevalence of pulp and periradicular diseases in a Brazilian subpopulation, correlating the prevalence with sex, age and most affected teeth. Methods: Data collected from medical records of patients treated at the Clinic of Specialization in Endodontics of the Federal University of Pernambuco between 2003 and 2010. The following variables were recorded for each patient: sex, age, affected teeth and diagnosed endodontic disease. Using Pearson's chi-square and Fisher's exact tests, the collected data analysis was set at a $5 \%$ significance level. Results: From all the treated teeth, $57 \%$ were diagnosed with pulp diseases, with the symptomatic irreversible pulpitis being the most prevalent ( $46.3 \%$ ), while among the diagnosed periradicular diseases ( $43 \%$ ), chronic apical periodontitis was the most prevalent $(81 \%)$. Pulp diseases were detected in men and women in an unequal mode $(p=0.008)$. Subjects under 40 years old had higher prevalence of pulp disease $(p=0.286)$, and patients over 50 years were most affected by periradicular diseases $(p=0.439)$. Maxillary incisors and mandibular first molars were the most affected teeth by endodontic diseases. Conclusions: In the evaluated subpopulation, the endodontic diseases were more prevalent in the maxillary incisive, affected indiscriminately individuals of different age groups and chronic apical periodontitis was the most prevalent diagnosed disease.
\end{abstract}

Keywords: Endodontics. Dental Pulp. Periapical Diseases. Epidemiology.

\section{Introduction}

In normal physiological conditions, the pulp tissue of a healthy tooth and its surrounding dentine is protected from the external environment by enamel and cementum. Nevertheless, aggressive agents like caries, dental trauma and restorative procedures may produce disruption of the tissue integrity that protects the pulp, allowing occurrence of infections in the dentin-pulp complex, eventually leading to a pulpal disease that may spread to the periradicular tissue ${ }^{1-2}$.

In Brazil, dental caries is one of the main damaging agents to dental pulp. A 2010 report on the oral health status of the Brazilian population,, issued by the Brazilian Ministry of Health ${ }^{3}$, showed that $76.1 \%$ of adolescents between $15-19$ years old had at least one decayed tooth. Among the individuals aged between 35-44 and 65-74 years, only $0.9 \%$ and $0.2 \%$ respectively, were caries-free.

Oral diseases are the fourth most expensive disease to treat in most industrialized countries $^{4}$, affecting not only the teeth but also the surrounding tissues and, in later stages, compromising the phonetic functions, nutrition, aesthetics ${ }^{5}$ and even the overall 
health status of the individual ${ }^{6}$. This situation calls for investment in prevention and programs to promote oral health by the decisionmakers to implement programs that should, ideally, rely on the real needs of a population. Therefore, data from endodontic epidemiological surveys may contribute to the improvement of this knowledge ${ }^{7}$.

Investigations on the prevalence of pulp and periradicular diseases in the Brazilian population produced few studies ${ }^{8-11}$ and most of them were conducted exclusively based on radiographic assessments for the diagnosis of such infections. Considering the importance of epidemiological investigations, the objective of this study was to determine the prevalence of pulp and periradicular diseases diagnosed in a Brazilian subpopulation, correlating this information to gender, age group and most affected teeth.

\section{Material and methods}

After approval by the Research Ethics Committee of the Federal University of Pernambuco-UFPE, information was collected from 1346 medical records of patients treated at the Specialization Course in Endodontics of UFPE, a reference institution for endodontic treatment in the Brazilian Northeastern region, between April 2003 and March 2010. Only medical records containing complete information on the medical and dental history were included.

From each medical record, the following variables were collected: sex, age, affected teeth and diagnosed endodontic diseases. The diagnosis of pulp and periradicular diseases was made by evaluating the following information: main complaint and pain symptomatology; examination of extra and intraoral tissues; tests of pulp vitality, including cold and heat sensitivity; clinical assessments of periapical health, including percussion and palpation; and interpretation of periapical radiographs.
The classification for the diagnosis of endodontic diseases was the one used by the American Association of Endodontists ${ }^{12}$, as follows: reversible pulpitis, symptomatic irreversible pulpitis, asymptomatic irreversible pulpitis, pulp necrosis, internal and/or external root resorption, acute apical periodontitis, chronic apical periodontitis, acute apical abscess, chronic apical abscess, phoenix abscess and flare up.

The collected data were analyzed using descriptive statistics, after which Pearson's chi-square and Fisher's exact tests were applied with the significance level set at 5\%. The Statistical Package for Social Sciences, version 21 (SPSS, Chicago, IL, USA) was used.

\section{Results}

One thousand and six hundred teeth from 1346 patients were examined. Most individuals $(n=908,67.5 \%)$ were female. More than half $(57.0 \%)$ of all treated teeth were diagnosed with pulp diseases.

Among the diagnosed pulp diseases, symptomatic irreversible pulpitis was the most prevalent (46.3\% pulp diseases, $26.38 \%$ endodontic diseases), while root resorption was the least prevalent ( $0.8 \%$ pulp diseases, $0.5 \%$ endodontic diseases). Chronic apical periodontitis was the most prevalent periradicular disease $(81 \%$ periradicular diseases, $34.81 \%$ endodontic diseases) while flare up was not diagnosed (0\%)

Regarding gender, pulp diseases were detected in men and women in an unequal mode $(p=0.008)$, as statistically significant differences were verified for symptomatic irreversible pulpitis, which affected more females $(p=0.005)$, and for asymptomatic irreversible pulpitis, which affected more males $(p<0.001)$. The periradicular diseases were diagnosed in men and women similarly $(\mathrm{p}=0.895)($ Table 1$)$

Table 1 - Prevalence of treated teeth due to pulp and periradicular pathologies according to gender.

\begin{tabular}{|c|c|c|c|c|c|c|c|}
\hline \multirow{3}{*}{ Pathologies } & \multicolumn{4}{|c|}{ Gender } & \multirow{2}{*}{\multicolumn{2}{|c|}{ Total }} & \multirow{3}{*}{$p$ value } \\
\hline & \multicolumn{2}{|c|}{ Male } & \multicolumn{2}{|c|}{ Female } & & & \\
\hline & $\mathrm{n}$ & $\%$ & $n$ & $\%$ & $\mathrm{n}$ & $\%$ & \\
\hline \multicolumn{8}{|l|}{ Pulp } \\
\hline & & & & & & & $\mathrm{p}^{(1)}=0.008^{*}$ \\
\hline Reversible Pulpitis & 8 & 2.4 & 10 & 1.7 & 18 & 2.0 & \\
\hline Symptomatic Irreversible Pulpitis & 132 & 40.1 & 290 & 49.7 & 422 & 46.3 & \\
\hline Asymptomatic Irreversible Pulpitis & 66 & 20.1 & 67 & 11.5 & 133 & 14.6 & \\
\hline Pulp Necrosis & 109 & 33.1 & 194 & 33.3 & 303 & 33.2 & \\
\hline Internal Root Resorption & - & - & - & - & 0 & 0 & \\
\hline External Root Resorption & 1 & 0.3 & 2 & 0.3 & 3 & 0.3 & \\
\hline Internal and External Root Resorption & 1 & 0.3 & 4 & 0.7 & 5 & 0.5 & \\
\hline Normal pulp (endodontic treatment with prosthetic purpose) & 12 & 3.6 & 16 & 2.7 & 28 & 3.1 & \\
\hline Total & 329 & 100.0 & 583 & 100.0 & 912 & 100.0 & \\
\hline \multicolumn{8}{|l|}{ Periradicular } \\
\hline & & & & & & & $\mathrm{p}^{(1)}=0.953$ \\
\hline Acute Apical Periodontitis & 7 & 3.0 & 18 & 4.0 & 25 & 3.6 & \\
\hline Chronic Apical Periodontitis & 192 & 82.4 & 365 & 80.2 & 557 & 81.0 & \\
\hline Acute Apical Abscess & 7 & 3.0 & 15 & 3.3 & 22 & 3.2 & \\
\hline Chronic Apical Abscess & 27 & 11.6 & 56 & 12.3 & 83 & 12.1 & \\
\hline Phoenix Abscess & - & - & 1 & 0.2 & 1 & 0.1 & \\
\hline Flare Up & - & - & - & - & 0 & 0 & \\
\hline Total & 233 & 100.0 & 455 & 100.0 & 688 & 100.0 & \\
\hline
\end{tabular}

$\left({ }^{*}\right)$ : Significant association at the level of $5.0 \%$.

(1): Using Fisher's exact test. 
There were no statistically significant differences between different age groups and the prevalence of endodontic diseases $(p=0.388)$ (Table 2$)$. The prevalence of pulp diseases was higher in patients under 50 years old, whereas the age group 50 to 59 years showed the lowest prevalence $(p=0.286)$. The periradicular diseases affected a greater proportion of patients over 50 years of age, while individuals under 18 years were less affected $(p=0.439)$.

Pulp and periradicular diseases affected the maxillary and mandibular teeth with the same frequency $(p=0.581)$. In the maxilla, the second molars $(75.6 \%)$ were the most affected teeth by pulp diseases, while the central and lateral incisors $(57.5 \%)$ were the most affected by periradicular diseases $(p<0.001)$. In the mandible, the teeth most affected by the pulp diseases were the third molars $(82.6 \%)$, while the first premolars $(49.2 \%)$ were the most affected by periradicular diseases $(p=0.107)$ (Table 3$)$. The dental elements most affected by endodontic diseases in the maxilla were the incisors $(31.87 \%)$, while in the mandible, the first molars were the most affected $(41.28 \%)$.

\section{Discussion}

This cross-sectional study had as its primary objective describing the prevalence of pulp and periradicular diseases in a Brazilian urban subpopulation by analysis of medical records of patients treated at the clinic of the Postgraduate Course in Endodontics in Recife (PE), in the Brazilian Northeastern region. Since the studied patients do not represent a random sample of the population, but individuals who sought dental treatment, the extrapolation of results for the general Brazilian population should be made with caution. However, we emphasize that this dental service is a reference in the region for endodontic care, which may portray the reality of the geographical region reached by our clinic.

The results of this study demonstrate that the most prevalent endodontic disease in both sexes was chronic apical periodontitis. The prevalence of chronic apical periodontitis (34.81\%) agreed with studies conducted in other populations in Buenos Aires in Argentina $^{13}$, Bucaramanga and Floridablanca in Colômbia ${ }^{14}$, and Barcelona in Spain ${ }^{15}$, where it ranged $27 \%$ to $49 \%$. However, these results were higher than those reported in other surveys conducted in English ${ }^{16}$ (4.1\%), Scottish ${ }^{17}(5.8 \%)$ and Kosovan ${ }^{18}(12.3 \%)$ populations. The discrepancies observed among these studies may be justified by the different degrees of human development among these populations.
The prevalence of chronic apical periodontitis in Brazilian subpopulations was target of previous studies ${ }^{11,19}$, which found a prevalence of chronic apical periodontitis of $3.4 \%{ }^{11}$ and $5.9 \%{ }^{19}$, respectively, whereas in our study, which evaluated a larger population sample than those studies, we detected a higher prevalence, i.e., $34.81 \%$.

The discrepancies observed between the results of the mentioned studies may be justified by lack of homogeneity in the analyzed population, lack of standardized evaluation methods, and the populations' general level of oral health, factors that hamper comparing results from different studies.

The results of this study showed that the pulp diseases were detected in men and women in an unequal mode $(p=0.008)$, where the symptomatic irreversible pulpitis affected more females $(p=0.005)$, while asymptomatic irreversible pulpitis affected more males $(p<0.001)$. This difference may be explained by the fact that women take more care of their health and appearance than men8, which may lead them to seek dental care immediately in symptomatic cases, while men choose to postpone treatment ${ }^{20}$. On the other hand, men and women presented a similar prevalence of periradicular diseases $(p=0.953)$, confirming what has been previously reported in other studies ${ }^{11,19,21}$.

The results presented here indicated that the prevalence of pulp diseases was higher in people under 50 years of age, whereas periradicular diseases affected more patients over 50 years of age. There were no statistically significant differences between the age groups and the prevalence of endodontic diseases $(\mathrm{p}=0.388)$. These findings agree with those of Kamberi et al. ${ }^{18}$ (2011), Paes da Silva Ramos Fernandes et al.11 (2013), Peters et al. ${ }^{21}$ (2011), Terças et al. ${ }^{19}$ (2006), who observed an increase in the prevalence of periradicular lesions with increasing patient age. According to Terças et al. ${ }^{19}$ (2006), this result is expected since, with increased age, the tooth is exposed to caries, periodontal disease, friction and various operative procedures that increase the risk of pulpal inflammation, which if not treated may progress to periapex.

In this study, the central and lateral incisors and the first molars were the teeth most affected by endodontic diseases. As reported by Al-Negrish ${ }^{22}$ and Berlinck et al. ${ }^{8}$ (2015), the reason for the incisors to be most the affected may be associated with dental traumas, which usually affect the teeth that are in anterior position and more prominent in the dental arch. On the other hand, the higher prevalence of the first molars may be related to their morphology, with multiple grooves that facilitate the largest plaque retention, and the fact that they are the first permanent teeth to erupt in the oral cavity ${ }^{23}$

Table 2 - Prevalence of treated patients due to pulp and periradicular pathologies according to age groups.

\begin{tabular}{|c|c|c|c|c|c|c|c|c|}
\hline \multirow{3}{*}{ Age Groups } & \multirow{3}{*}{ All patients } & \multicolumn{6}{|c|}{ Pathologies } & \multirow{3}{*}{$p$ value } \\
\hline & & \multicolumn{2}{|c|}{ Pulp } & \multicolumn{2}{|c|}{ Periradicular } & \multicolumn{2}{|c|}{ Both } & \\
\hline & & $n$ & $\%$ & $n$ & $\%$ & $n$ & $\%$ & \\
\hline & & & & & & & & $\mathrm{p}^{(1)}=0.388$ \\
\hline$\leq 18$ & 226 & 125 & 55.3 & 82 & 36.3 & 19 & 8.4 & \\
\hline $19-29$ & 300 & 155 & 51.7 & 116 & 38.7 & 29 & 9.7 & \\
\hline $30-39$ & 334 & 180 & 53.9 & 123 & 36.8 & 31 & 9.3 & \\
\hline $40-49$ & 266 & 139 & 52.3 & 105 & 39.5 & 22 & 8.3 & \\
\hline $50-59$ & 165 & 75 & 45.5 & 78 & 47.3 & 12 & 7.3 & \\
\hline$\geq 60$ & 55 & 26 & 47.3 & 25 & 45.5 & 4 & 7.3 & \\
\hline Total & 1346 & 700 & 52.0 & 529 & 39.3 & 117 & 8.7 & \\
\hline
\end{tabular}

(1): Using Pearson's chi-square test. 
Table 3 - Prevalence of treated teeth due to pulp and periradicular pathologies according to dental groups.

\begin{tabular}{|c|c|c|c|c|c|c|}
\hline \multirow{3}{*}{ Dental Groups } & \multicolumn{6}{|c|}{ Pathologies } \\
\hline & \multirow{2}{*}{$\begin{array}{c}\text { All } \\
\text { Teeth }\end{array}$} & \multicolumn{2}{|c|}{ Pulp } & \multicolumn{2}{|c|}{ Periradicular } & \multirow[t]{2}{*}{$p$ value } \\
\hline & & $n$ & $\%$ & $N$ & $\%$ & \\
\hline Maxillary & & & & & & $\mathrm{p}^{(1)}<0.001^{*}$ \\
\hline Incisors & 320 & 136 & 42.5 & 184 & 57.5 & \\
\hline Canines & 62 & 33 & 53.2 & 29 & 46.8 & \\
\hline $1^{\text {st }}$ Premolars & 160 & 90 & 56.3 & 70 & 43.8 & \\
\hline $2^{\text {nd }}$ Premolars & 164 & 105 & 64.0 & 59 & 36.0 & \\
\hline $1^{\text {st }}$ Molars & 212 & 139 & 65.6 & 73 & 34.4 & \\
\hline $2^{\text {nd }}$ Molars & 78 & 59 & 75.6 & 19 & 24.4 & \\
\hline $3^{\text {rd }}$ Molars & 8 & 5 & 62.5 & 3 & 37.5 & \\
\hline Subtotal & 1004 & 567 & 56.5 & 437 & 43.5 & \\
\hline Mandibular & & & & & & $p^{(1)}=0.107$ \\
\hline Incisors & 38 & 22 & 57.9 & 16 & 42.1 & \\
\hline Canines & 19 & 14 & 73.7 & 5 & 26.3 & \\
\hline $1^{\text {st }}$ Premolars & 61 & 31 & 50.8 & 30 & 49.2 & \\
\hline $2^{\text {nd }}$ Premolars & 93 & 50 & 53.8 & 43 & 46.2 & \\
\hline $1^{\text {st }}$ Molars & 246 & 138 & 56.1 & 108 & 43.9 & \\
\hline $2^{\text {nd }}$ Molars & 116 & 71 & 61.2 & 45 & 38.8 & \\
\hline $3^{\text {rd }}$ Molars & 23 & 19 & 82.6 & 4 & 17.4 & \\
\hline Subtotal & 596 & 345 & 57.9 & 251 & 42.1 & \\
\hline Total & 1600 & 912 & 57.0 & 688 & 43.0 & \\
\hline
\end{tabular}

$\left({ }^{\star}\right)$ : Significant association at the level of $5.0 \%$.

(1): Using Pearson's chi-square test.

Although the percentage of assessed maxillary teeth was higher than the mandibular ones, there was no significant difference between the maxilla and mandible in the incidence of teeth affected by endodontic diseases, which is consistent with the results of other authors ${ }^{18,24}$. On the other hand, the studies of Al-Negrish ${ }^{23}$ and Scavo et al. ${ }^{13}$ (2011) reported that in their studies the maxillary teeth were predominantly more affected in relation to the mandibular.

Although our results do not describe a random sample of the Brazilian population, but accounting that Brazil is a continentwide country, these results provide relevant information on the prevalence of pulp and periradicular diseases that most affect a subpopulation this may help to define new treatment strategies and prevention of endodontic diseases.

Based on the results obtained in this study, we conclude that in the evaluated subpopulation:

- chronic apical periodontitis and symptomatic irreversible pulpitis were the most prevalent diagnosed endodontic diseases;

- symptomatic irreversible pulpitis affected more females, whereas asymptomatic irreversible pulpitis was more prevalent in males;

- endodontic disease affected indiscriminately individuals of different age groups and the maxillary and mandibular teeth;

- incisors and first molars were the most affected teeth by endodontic diseases.

\section{References}

1. Love RM. Intraradicular space: what happens within roots of infected teeth? Ann R Australas Coll Dent Surg. 2000 Oct;15:235-9.

2. Nair PN, Pajarola G, Schroeder HE. Types and incidence of human periapical lesions obtained with extracted teeth. Oral Surg Oral Med Oral Pathol Oral Radiol Endod. 1996 Jan;81(1):93-102.

3. Brazil. Brazilian Ministry of Health. [SB BRAZIL 2010: National Research on Oral Health: Main Results]. Brasilia: Ministry of Health; 2010 [cited
2015 Jun 17]. 92p. Available from: http://dab.saude.gov.br/CNSB/ sbbrasil/arquivos/projeto_sb2010_relatorio_final.pdf. Portuguese.

4. Petersen PE, Bourgeois D, Ogawa H, Estupinan-Day S, Ndiaye C. The global burden of oral diseases and risks to oral health. Bull World Health Organ. 2005 Sep;83(9):661-9.

5. Corrêa-Faria P, Paixão-Gonçalves S, Paiva SM, Martins-Júnior PA, VieiraAndrade RG, Marques LS, et al. Dental caries, but not malocclusion or developmental defects, negatively impacts preschoolers' quality of life. Int J Paediatr Dent. 2016 May;26(3):211-9. doi: 10.1111/ipd.12190.

6. Cotti E, Mercuro G. Apical periodontitis and cardiovascular diseases: previous findings and ongoing research. Int Endod J. 2015 Oct;48(10):92632. doi:10.1111/iej.12506.

7. Kirkevang LL. Root canal treatment and apical periodontitis: what can be learned from observational studies? Endod Topics. $2011 \mathrm{Mar} ; 18(1): 51-61$.

8. Berlinck T, Tinoco JM, Carvalho FL, Sassone LM, Tinoco EM. Epidemiological evaluation of apical periodontitis prevalence in an urban Brazilian population. Braz Oral Res. 2015;29:51. doi: 10.1590/18073107BOR-2015.

9. Costa TH, de Figueiredo Neto JA, de Oliveira AE, Lopes e Maia M de F, de Almeida AL. Association between chronic apical periodontitis and coronary artery disease. J Endod. 2014 Feb;40(2):164-7. doi: 10.1016/j. joen.2013.10.026.

10. Hebling E, Coutinho LA, Ferraz CC, Cunha FL, Queluz DP. Periapical status and prevalence of endodontic treatment in institutionalized elderly. Braz Dent J. 2014;25(2):123-8.

11. Paes da Silva Ramos Fernandes LM, Ordinola-Zapata R, Húngaro Duarte MA, Alvares Capelozza AL. Prevalence of apical periodontitis detected in cone beam CT images of a Brazilian subpopulation. Dentomaxillofac Radiol. 2013;42(1):80179163. doi: 10.1259/dmfr/80179163.

12. AAE Consensus Conference Recommended Diagnostic Terminology. J Endod. 2009 Dec;35(12):1634.

13. Scavo R, Martinez Lalis R, Zmener O, Dipietro S, Grana D, Pameijer $\mathrm{CH}$. Frequency and distribution of teeth requiring endodontic therapy in an Argentine population attending a specialty clinic in endodontics. Int Dent J. 2011 Oct;61(5):257-60. doi: 10.1111/j.1875-595X.2011.00069.x.

14. Moreno JO, Alves FR, Gonçalves LS, Martinez AM, Rôças IN, Siqueira JF Jr. Periradicular status and quality of root canal fillings and coronal restorations in an urban Colombian population. J Endod. 2013 May;39(5):600-4. doi: 10.1016/j.joen.2012.12.020. 
15. Abella F, Patel S, Durán-Sindreu F, Mercadé M, Bueno R, Roig M. An evaluation of the periapical status of teeth with necrotic pulps using periapical radiography and cone-beam computed tomography. Int Endod J. 2014 Apr;47(4):387-96. doi: 10.1111/iej.12159.

16. Di Filippo G, Sidhu SK, Chong BS. Apical periodontitis and the technical quality of root canal treatment in an adult sub-population in London. $\mathrm{Br}$ Dent J. 2014 May;216(10):E22. doi: 10.1038/sj.bdj.2014.404.

17. Dutta A, Smith-Jack F, Saunders WP. Prevalence of periradicular periodontitis in a Scottish subpopulation found on CBCT images. Int Endod J. 2014 Sep;47(9):854-63. doi: 10.1111/iej.12228.

18. Kamberi B, Hoxha V, Stavileci M, Dragusha E, Kuçi A, Kqiku L. Prevalence of apical periodontitis and endodontic treatment in a Kosovar adult population. BMC Oral Health. 2011 Nov 29;11:32. doi: 10.1186/14726831-11-32.

19. Terças AG, de Oliveira AE, Lopes FF, Maia Filho EM. Radiographic study of the prevalence of apical periodontitis and endodontic treatment in the adult population of São Luís, MA, Brazil. J Appl Oral Sci. 2006
Jun;14(3):183-7.

20. Courtenay WH. Constructions of masculinity and their influence on men's well-being: a theory of gender and health. Soc Sci Med. 2000 May;50(10):1385-401.

21. Peters LB, Lindeboom JA, Elst ME, Wesselink PR. Prevalence of apical periodontitis relative to endodontic treatment in an adult Dutch population: a repeated cross-sectional study. Oral Surg Oral Med Oral Pathol Oral Radiol Endod. 2011 Apr;111(4):523-8. doi: 10.1016/j.tripleo.2010.10.035.

22. Al-Negrish AR. Incidence and distribution of root canal treatment in the dentition among a Jordanian sub population. Int Dent J. 2002 Jun;52(3):125-9.

23. Mukhaimer R, Hussein E, Orafi I. Prevalence of apical periodontitis and quality of root canal treatment in an adult Palestinian sub-population. Saudi Dent J. 2012 Jul;24(3-4):149-55. doi: 10.1016/j.sdentj.2012.02.001.

24. Wayman BE, Patten JA, Dazey SE. Relative frequency of teeth needing endodontic treatment in 3350 consecutive endodontic patients. J Endod. 1994 Aug;20(8):399-401. 